\title{
trabahonecessário
}

issn: $1808-799 \mathrm{X}$

ano 3 número $3-2005$

\section{BRASIL E A POLÍTICA ECONÔMICO-SOCIAL: ENTRE O MEDO E A ESPERANÇA}

Gaudêncio Frigotto[i]

A justeza de um balanço de um determinado período histórico depende, em grande parte, da relação entre determinantes conjunturais e o processo histórico de longo prazo. Vale dizer, a relação entre o conjuntural e o estrutural. Isto vale, sem dúvida, para analisar o que vem se passando com os primeiros 20 meses do governo Lula da Silva. Neste breve artigo, mais que uma análise que permita conclusões enfáticas, buscarei dar elementos para situar porque a eleição de Lula representou, para as forças e movimentos sociais ligados à luta pela superação das estruturas de uma das sociedades mais injustas e desiguais do mundo, tantas esperanças e porque, após 20 meses de governo, o sentimento de muitos é de desapontamento e perplexidade.

Em que projeto as forças e movimentos sociais de esquerda apostaram ao eleger o governo Lula e o que divide e desaponta estas forças e movimentos sociais? Numa breve síntese, José Luiz Fiori (2002) nos indica que no Brasil três projetos societários "conviveram e lutaram entre si durante todo o século XX".

O primeiro projeto nasceu das idéias do liberalismo econômico centrado na política monetarista ortodoxa e na defesa intransigente do equilíbrio fiscal e do padrão-ouro. Ao 
longo do século XX é a concepção dominante incorporada pelos ministros da fazenda, C. Castro, Eugênio Gudin, Otávio Bulhões e Roberto Campos. E este projeto, destaca Fiori, "foi o berço da estratégia econômica do governo Cardoso" cujo ministro, ao longo de dois mandatos, foi Pedro Malan. Projeto que sempre se contrapôs ao que Fiori denomina de "nacional desenvolvimentismo" ou "desenvolvimentismo conservador" presente na Constituinte de 1891 e nos anos 30 e que a literatura política e econômica tem denominado de "era Vargas". Passado justo meio século da morte de Getúlio Vargas um dos debates polêmicos que ocupa o cenário político é justamente a reforma da legislação trabalhista herdada deste período.

O resultado da dominância do projeto societário firmado nas teses do liberalismo econômico centrado no ajuste fiscal e, em alguns períodos históricos do projeto do nacionalismo conservador e populismo, tem sido a configuração de uma das sociedades de maior desigualdade econômica, social, cultural e educacional do mundo, onde se legaliza o privilégio e a própria desigualdade. Uma sociedade legalista, mas profundamente injusta e, portanto, ilegítima. Como indicam PETRAS e VETMEYER, (2001) particularmente os anos de governo de Fernando Henrique Cardoso tornaram o Brasil seguro para o capital.

Estes dois projetos, especialmente o do liberalismo conservador monetarista, opunham-se a um terceiro projeto: o de "desenvolvimento econômico nacional e popular". Esta terceira alternativa "nunca ocupou o poder estatal, nem comandou a política econômica de nenhum governo republicano, mas teve enorme presença no campo da luta ideológico-cultural e das mobilizações democráticas ( Ib.)

Dois eixos básicos e profundamente relacionados sintetizam o horizonte deste projeto que aglutina forças bastante heterogêneas no campo de esquerda:

A luta por construir uma nação com a sua história, cultura, língua e valores que constituem a base de um relacionamento autônomo e soberano com outras nações e povos. Uma ruptura, portanto, com os processos de colonização e subserviência aos centros hegemônicos do capital. Isto tem como exigência preliminar uma renegociação da dívida externa sob novas bases e uma outra postura frente aos organismos internacionais. 
Concomitantemente, no plano interno, impõe-se uma ruptura com as forças que mantêm a desigualdade abismal na sociedade brasileira em todos os âmbitos. Trata-se de atacar reformas estruturais inadiáveis: a reforma agrária e a taxação das grandes fortunas, com o intuito de acabar com o latifúndio e a altíssima concentração da propriedade da terra e, ao mesmo tempo, afirmar um novo projeto desenvolvimento com justiça social; a reforma tributária, com o objetivo de inverter a lógica regressiva dos impostos, em que os assalariados e os mais pobres pagam mais, corrigindo assim a enorme desigualdade de renda; a reforma social, estatuindo uma esfera pública democrática que permita a garantia dos direitos sociais (Educação, saúde, trabalho, cultura, aposentadoria, etc.) e direitos subjetivos. Trata-se, no presente, de combater o ideário neoconservador ou neoliberal do ajuste, da desregulamentação, flexibilização dos direitos e privatização do patrimônio público e recuperar a capacidade do Estado de fazer política econômica e social.

Para alguns setores destas forças trata-se de lutar para ir além das relações sociais capitalistas mediante um projeto societário socialista, pois a efetiva igualdade de condições entre os seres humanos é inviável dentro do capitalismo. Ademais, o capitalismo hoje, para manter-se, tem que destruir um a um os direitos duramente conquistados, especialmente, pela classe trabalhadora ao longo dos séculos XIX e XX.

Um aspecto que pode nos ajudar a entender os impasses do governo Lula situa-se no fato de que já em julho de 2002, para viabilizar sua eleição, assinou a carta compromisso com o Fundo Monetário Internacional em operação montada pelo governo Fernando Henrique Cardoso. Neste momento, para Chesnais, se configurava uma opção desviante. Eleito para formar a base de sustentação do governo, estruturou alianças e compromissos com representantes dos três projetos aqui assinalados.

De todo modo, o elemento novo que gerou amplas expectativas de mudanças mais profundas é que pela primeira vez em nossa história assumiam o poder do Estado Nacional forças políticas cujas biografias estão vinculadas ao embate teórico e à luta ideológica por um projeto de desenvolvimento nacional popular. O Partido dos Trabalhadores (PT) que elegeu o Presidente Lula, com o apoio dos movimentos sociais e o "novo sindicalismo" representado pela Central Única dos Trabalhadores (CUT), fez da 
experiência do orçamento participativo da Prefeitura de Porto Alegre e de sua ampliação para outras prefeituras e estados governados pelo PT e outras partidos de esquerda, uma alavanca de campanha. Trata-se, sem dúvida, de uma inovação fecunda no processo de participação democrática popular e de uma nova relação ente Estado e sociedade. Não foi por acaso que o Brasil e a cidade de Porto Alegre se constituíram no espaço para realização dos Fóruns Mundiais Sociais e os Fóruns Mundiais de Educação, cuja agenda é uma alternativa ao processo predatório e destrutivo de globalização ou mundialização do capital.

Uma análise das propostas de Programa de Governo do candidato Lula nas áreas econômica e social nos indica que o ideário era de que "um outro Brasil é possível", pautando-se dentro de um projeto alternativo de desenvolvimento tendo como suporte uma ampla base social. Na avaliação de Ricardo Carneiro (2003), professor do Instituto de Economia da UNICAMP, que participou da equipe que elaborou a proposta econômica de governo do então candidato Lula, muito cedo o rumo que se tomou foi outro, tanto na área econômica quanto nas demais áreas. Isto o levou a sair da assessoria econômica do governo.

O balanço dos primeiros 20 meses de governo, portanto, não sinaliza claramente medidas na direção de um projeto de desenvolvimento Nacional Popular. Ao contrário, mostra como as trincheiras das forças dos projetos liberal conservador e do nacionalismo conservador estão impregnadas no aparelho do Estado e na sociedade civil, no governo e no PT, e na CUT.

No âmbito da política econômica as análises críticas apontam que o governo Lula segue dominantemente os fundamentos das reformas calcadas nas teses liberais do monetarismo e ajuste fiscal. A Reforma da Previdência, o superávit primário recorde, as indicações em relação à autonomia do Banco Central e o Acordo de Livre Comércio das Américas, são definições ou indefinições políticas que afirmam esta continuidade. $\mathrm{Na}$ mesma direção parecem apontar a reforma trabalhista e a reforma universitária que estão em curso.

Trata-se de um cenário que faz da análise de Perry Anderson (2002) sobre os governos 
eleitos por forças de centro esquerda ou esquerda nos anos 90 (Inglaterra, Alemanha, França, Espanha, Portugal, Chile, Peru, entre outros) e que acabaram completando as reformas da direita, numa sinalização preocupante. Ao referir-se à eleição de Luiz Inácio Lula da Silva, Anderson sinalizava que o seu governo não estava fora desta possibilidade, ainda que reconhecesse que vinha de uma história com uma base social diversa e que poderia fazer a diferença, sendo uma alternativa singular não só para o Brasil, mas para o mundo. Apontava, porém, quatro exigências, para ele imprescindíveis, para que isso pudesse ocorrer: não confundir os votos ganhos com o poder que deteria; ter um projeto alternativo claro e um grupo coeso na busca de sua concretização; vincular este projeto aos movimentos sociais organizados e identificar o inimigo, sem subestimá-lo. Destas quatro condições apenas a primeira, talvez, esteja presente.

O que desaponta e confunde o campo da esquerda hoje no Brasil é de que as forças conservadoras, externas e internas, que temiam a vitória de Lula, estão satisfeitas. Por outro lado, o pensamento crítico nacional e internacional, que não desconhece o peso da herança recebida historicamente e da era Fernando H. Cardoso, e, ao mesmo tempo, que não tinha a expectativa de mudanças revolucionárias, mostra-se cada vez mais cético e dividido. Talvez, se inverta, hoje, a relação esperança e medo. Se a vitória de Lula indicava que a "esperança venceu o medo", neste momento o sentimento do campo mais crítico é de que "o medo está vencendo a esperança".

Uma síntese emblemática do que sinalizo aqui, encontramos nas recentes avaliações do Governo Lula feitas por José Saramago, Prêmio Nobel de Literatura de 1998 e pelo escritor, compositor e cantor Chico Buarque.

Em outubro de 2003 Saramago advertia que Lula não podia ser transformado num Dom Sebastião (salvador da pátria): Não peçam milagres a um homem. Mesmo que este homem se chame Lula da Silva. Ele está fazendo o seu trabalho, e o Brasil não é um planeta que possa resolver seus problemas isoladamente (...) vai levar anos (....) Lula da Silva não salvará o Brasil se o Brasil não quiser ser salvo. Passado um ano o mesmo Saramago mostra sua perplexidade. Lula não chegou a se tornar um dom Sebastião, e ainda bem. Mas agora não sei exatamente quem é. Tenho a impressão que deixou de ser o Lula que conhecíamos. O poder tem destas coisas, vira os políticos como se eles fossem 
uma peúga. A primeira viragem chama-se pragmatismo, a segunda oportunismo, a terceira conformismo. A partir daqui, o melhor é deixar de contar (Saramago, 2004).

Chico Buarque, por sua vez, expressa o pensamento de quadros do campo de esquerda que concordam com a análise do governo de que o primeiro passo era de afirmar a estabilidade econômica e ganhar a confiança internacional. Isto teria sido atingido. Agora se poderia trabalhar a dívida social. Acho que ele está fazendo o que tem que fazer e eu tenho confiança pessoal no Lula. Ele não deve estar satisfeito de estar seguindo a receita que tem que ser seguida para conseguir uma certa estabilidade (...). Tenho a esperança que a partir do terceiro ano, ele (Lula) possa fazer não só o que precisa ser feito, mas o que ele quer e prometeu fazer (Chico Buarque, 2004)

Estas duas avaliações recentes feitas no mês de setembro de 2004, balizam diferentes opções e atitudes das forças de esquerda que, pela primeira vez na história do país, assumem o governo nacional com a possibilidade de implementar um projeto de desenvolvimento Nacional Popular com as reformas e mudanças acima assinaladas. Estas diferentes opções se dão no campo político-partidário, no campo sindical, nos movimentos sociais e nos quadros de intelectuais historicamente comprometidos com estas mudanças. O quadro conjuntural é de uma clara divisão da esquerda e uma pressão poderosa das forças conservadoras.

No campo político partidário o sentido que foram assumindo as reformas levou a uma crescente divergência interna no PT e partidos de esquerda, com reiteradas sanções aos parlamentares discordantes, mesmo que alegassem coerência programática, com o desfecho da expulsão de uma senadora e três deputados federias do PT. Esta decisão deflagrou o início da formação de um novo partido, PSOL (Partido Socialismo e Liberdade.) cujas assinaturas para se legalizar estão sendo colhidas neste momento. Vários intelectuais fundadores do PT são hoje signatários da fundação deste novo partido, assim como setores dos movimentos sociais e sindical, fraturando a base social que apoiou a eleição de Lula. O resultado é um processo de anulação política da esquerda e fortalecimento dos interesses conservadores, como bem explicita Francisco de Oliveira .

Se presenta, entonces, la paradoja de que las fuerzas que ganaron las elecciones luchan entre sí, en tanto que las clases dominantes provocan los conflictos: no es otro el 
caso de la reforma agraria en Brasil. El Movimiento de los Sin Tierra (MST) intenta obtener del gobierno el cumplimiento de la cantidad de asentamientos necesarios, y el gobierno no realiza la reforma agraria, talvez no por falta de voluntad político sino por los encuadramientos fiscales superavitarios impuestos por el FMI, en tanto que los medios de comunicación exageran el conflicto entre MST y gobierno. En consecuencia, ambos se debilitan y las posiciones anti-reforma agraria comienzan a crecer.

(Oliveira, 2004 p. 116).

Neste contexto, o MST vem adotando uma política independente e de não rompimento com o governo, buscando em seu interior alguns aliados históricos de suas bandeiras e, ao mesmo tempo, criticando a política econômica e seguindo sua estratégia de ocupação de terras improdutivas, luta pela reforma agrária e por um projeto alternativo de desenvolvimento econômico-social, cultural e educativo baseado na justiça e igualdade social. A data dos festejos da pátria de sete de setembro foi marcada, sob a liderança do MST, pela marcha do "grito dos excluídos" em todo o país. João Pedro Stédile, destacado líder nacional do MST, reiterou o que vem fazendo sistematicamente em relação á política econômica, destacando que o "governo deveria fazer uma autocrítica sobre a relação com o FMI e que é preciso ter coragem para mudar a política econômica". Segundo Stédile, o presidente Luiz Inácio Lula da Silva age certo ao pedir à população para ser mais patriota, mas deveria "rever algumas diretrizes que afetam a soberania nacional".[ii]

As forças conservadoras, ligadas ao latifúndio e à estrutura de privilégio, como assinala Oliveira, valem-se permanentemente dos meios de comunicação que controlam para criar uma opinião pública que caracteriza o MST como violento, perigosos e promotor da desordem e insegurança social. Justamente na Semana da Pátria a revista VEJA[iii] divulga uma ampla matéria que acusa o MST de ensinar, em suas escolas, o ódio e a luta de classe para as crianças.

Esta matéria foi produzida duas semanas após a /l Conferência de Educação do Campo onde se evidencia e se afirma, graças, sobretudo, ao MST, uma nova concepção educativa vincada na realidade econômico-social e cultural dos educandos. Contrariamente ao que acusa a revista VEJA, as escolas trabalham valores da solidariedade, do cooperativismo e desenvolvem no educando a capacidade de análise e de leitura do mundo em que vivem, dentro da perspectiva da pedagogia de Paulo Freire. Certamente não são escolas que ensinam a pedagogia da submissão e do conformismo a uma sociedade profundamente 
desigual. A existência de quatro milhões de famílias sem terra, que constituem 20 milhões de adultos, jovens e crianças, num país continental, é uma realidade tão brutal e violenta que não se pode imaginar de que os que são atingidos não a analisem e critiquem.

Outro movimento social que ganha espaço é o movimento negro. O Brasil é uma nação que tem quase metade de sua população descendentes da raça negra. Uma das estratégias das classes dominantes tem sido o de mascarar o preconceito e discriminação racial. Diferentes indicadores sócio-econômicos, culturais e educacionais evidenciam de forma inequívoca a discriminação e o preconceito. Como analisa o senador da República Paulo Paim (2004), permanece forte na sociedade brasileira aquilo que Abdias Nascimento denunciava em 1949 - o delito de ser negro. "Basta um negro ser detido por qualquer coisa insignificante - assim como não ter uma carteira de identidade - para ser logo tratado como se já fosse criminoso. Dir-se-ia que a polícia considera o homem de cor um delinqüente nato, e está criando o delito de ser negro”. A criminalização preconceituosa do negro não está apenas no aparato policial. Está presente nas instituições da justiça e em outras instituições e no imaginário social construído em nosso processo histórico.

Por sua crescente organização e lutas por direitos até agora negados, ganhou espaço no governo Lula. A indicação de Gilberto Gil para o Ministério da Cultura expressa esta importância. Não se trata de um movimento que tenha um projeto político e de classe mais amplo e orgânico, como o MST. Por isso, suas críticas aos rumos mais amplos da política do governo Lula são raras. As lutas mais amplas do movimento negro são no campo das políticas de inclusão ou de "discriminação positiva". No momento está em pauta a cota de vagas nas Universidades para afro-descententes.

Um dos pontos críticos no governo Lula situa-se justamente no movimento sindical representado pela CUT, definido como "o novo sindicalismo", onde o Partido dos Trabalhadores se originou. A tendência majoritária deste sindicalismo - Articulação Sindical - tem funções executivas no governo Lula tanto no comando político quanto em postos dos fundos de pensão. Para Boito (2003) esta tendência majoritária representa o "novo corporativismo operário" com um grupo ocupando cargos de elevada remuneração. Este grupo criaria "uma situação próxima àquela designada por Nicos Poulantzas de 'classe detentora' do aparelho de Estado". Na mesma direção e de forma mais incisiva Francisco 
de Oliveira, um dos fundadores do PT, identifica uma forte identidade programática do governo Fernando $\mathrm{H}$. Cardoso e o atual governo. Não se trata de equívoco e nem de toma de empréstimo de programa, mas de uma verdadeira nova classe social, que se estrutura sobre, de um lado, técnicos e economistas doublés de banqueiros, núcleo duro do PSDB, e trabalhadores transformados em operadores de fundos de previdência, núcleo duro do PT. (Oliveira, 2003 p.147). A cisão, dentro da CUT, fica cada vez mais clara. Isto fica elucidado pela divisão e pelo embate que se trava dentro do Sindicato Nacional dos Docentes das Instituições de Ensino (ANDES), atualmente o maior sindicato filiado à CUT.

Por certo se as análises acima se confirmarem um projeto alternativo de sociedade e de desenvolvimento, mesmo que nos termos de um projeto Nacional Popular, estará irremediavelmente adiado. Mais que isto, estará se decretando uma derrota profunda do campo da esquerda com efeitos de longo prazo.[iv] Esta situação, de imediato, vem provocando uma anulação da ação política justamente do sindicalismo, que teve um papel crucial na derrota da ditadura militar e na resistência às políticas de associação e subserviência aos organismos do grande capital predatório na década de 1990.

Com este quadro de esfacelamento e anulação do campo da esquerda e o poder político, econômico e de formação de opinião, pela grande mídia, das elites que mantêm, por cinco séculos, o Brasil como "um gigante com pés de barro", as reformas estruturais ficam uma vez mais adiadas, num eterno castigo de Síssifo. Sem atacar as mudanças estruturais resta a adoção de políticas focalizadas de inserção social atacando-se o problema pelos seus efeitos. (Castell, 1997). Políticas de alívio à pobreza que, isoladas, mantêm e realimentam as estruturas que a produzem. O novo na política brasileira no governo Lula seria, ao mesmo tempo, enfrentar as reformas estruturais e a renegociação da dívida e dos juros da dívida externa e interna e ir efetivando as políticas distributivas emergenciais. Isto, contudo, não pode ser feito sem contrariar interesses dos organismos internacionais, guardiões da rentabilidade máxima do grande capital, mormente o financeiro, e dos interesses de grupos nacionais vinculados a este grande capital ou ao latifúndio e à escandalosa concentração de renda[v].

Os riscos do campo da esquerda são diversos e profundos. Dentre os riscos, o mais grave é de se cumprir a advertência de Perry Anderson de que o governo Lula não estava imune 
de reiterar a tradição dos anos 1990 dos governos que se elegeram pelo campo da esquerda e fizeram as reformas da direita. Mais letal, se isto representa uma opção político-ideológica. Se a hipótese que setores da esquerda defendem é a de que esta primeira fase do governo não podia ser diferente, mas que agora pode mudar, o risco, igualmente nefasto, é de que a divisão da esquerda, de todo modo, empurre o governo Lula a formar sua base cada vez mais pelo centro e direita. O resultado, na prática, será o mesmo: a continuidade das reformas conservadoras.

Em suma, o terreno por onde pode mover-se a esquerda não é outro senão o da contradição. O que de imediato, talvez, seja urgente e necessário é seguir a indicação de Gramsci e efetivar um inventário crítico do que nos trouxe até aqui. $O$ início da elaboração crítica é a consciência daquilo que somos realmente, isto é, um 'conhece-te a ti mesmo' como produto do processo histórico até hoje desenvolvido, que deixou em ti uma infinidade de traços recebidos sem benefício do inventário. Deve-se fazer, inicialmente, este inventário. (Gramsci, 1978 p.12). Por certo, neste inventário, é crucial ter presente que, como nos lembra o poeta João Cabral de Melo Neto, se entrarmos no pântano de terno branco e sairmos de terno branco "a poesia perdeu a graça".

Referências bibliográficas

ANDERSON, P. Seminário Pós-neoliberalismo III. Rio de Janeiro, Laboratório de Políticas Públicas da UERJ, 26.11.2002.

BOITO, A. A hegemonia neoliberal no governo Lula. Revista Crítica marxista no 17, São Paulo, Editora Revan, 2003, p.10-36.

BUARQUE, C. Espero que Lula possa fazer o que ele quer e prometeu. Rio de Janeiro, Jornal O globo, Caderno o País, . 04.09.2004, p. 14.

CARNEIRO, R. Jornal da UNICAMP, Edição 130. Campinas, SP. 22 a 28 de setembro de 2003.

CASTELL, R. As armadilhas da exclusão. In: Vários. Desigualdade e a questão social. São Paulo, EDUC, 1997.

FIORI, J. L. Nome aos Bois. Instituto da Cidadania. São Paulo, Fundação Perseu Abramo, 2002.

GRAMASCI, A . Concepção dialética da história. Rio de Janeiro, Civilização Brasileira, 1978.

HOBSBAWM, E. Adiós al movimiento obrero clásico? MADRID (Tradução por Gabriel Pasquini).Disponible em: Biblioteca en linea. http://www.lasbibliotecas.net/librosgratis/h.htm. Outubro de 2003.

OLIVEIRA, F. De, Hay vias abiertas para América Latina? In: BORON, A (compilador) 
Nueva Hegemonía Mundial - Alternativas de cambio y movimientos sociales . Buenos Aires, CLACSO, 2004,

OLIVEIRA, F. de. O Ornitorrinco. In Crítica à razão dualista - O Ornitorrinco. São Paulo, Editora Boitempo. 2003. p.121-150

PAIM, P. Jornal O Globo, 24.02,2004, p7

PETRAS, J. e Veltmeyer, H. Brasil de Cardoso - a desapropriação do país. Petrópolis, editora Vozes,2001

SARAMAGO, J. Lula deixou de ser o Lula que conhecíamos. Rio de Janeiro, Jornal $O$ Globo. Caderno o País. 03.09.2004, p.12.

SOARES, L. T, SADER, E. GENTILI, R e BENJAMIN, C. Governo Lula - decifrando o enigma. São Paulo, Editora Viramundo, 2004.

[i] Doutor em Ciências Humanas. Professor Titular Visitante na Faculdade de Educação da Universidade do Estado do Rio de Janeiro e Professor Titular, associado, no Programa de Pós-graduação em Educação da Universidade Federal Fluminense. Membro do Comitê Diretivo do Conselho Latino-americano de Ciências Sociais (CLACSO).Membro da equipe que produziu a proposta de política educacional do candidato Luis Inácio da Silva (Lula).

[ii] Jornal O Globo. Rio de Janeiro, Caderno o País, 08 de setembro de 2004, p. 5.

[iii] Ver reportagem da revista VEJA, №36, São Paulo, 08 de setembro de 2004, p. 9 e 4649.

[iv] .Um balanço mais rigoroso das bases dentro das quais se originou o PT talvez nos mostre, como assinalam Boito (2003) e o historiador Eric Hobsbawm (2003), que hegemonicamente o mesmo não se caracterizou por um partido de esquerda com um projeto socialista, embora dentro dele existissem e existam grupos com este projeto. A partir da derrota por Fernando Collor de Mello o grupo hegemônico do PT (leia-se também da CUT), que buscou viabilizar a vitória de Lula ao longo da década de 1990, foi explicitando, de forma cada vez mais clara, a opção de um partido acomodado na ordem do capital. Nas palavras do atual presidente do partido José Genoino: Não temos referência teórica e isso é ótimo porque atualmente, com essa crise de paradigmas, é muito ruim ter uma espécie de tutor. Hoje temos que contar com várias teorias, com várias reflexões, para elaborar um projeto próprio para a realidade brasileira. (Genoino, J. Revista Veja, 11.08. 2003).

[v] .Para uma balanço mais amplo do governo Lula em relação à políticas e movimentos sociais, política nacional e internacional e política econômica ver Laura Tavares Soares e outros autores (2004).

volta 